\title{
Arterial blood pressure in patients with Parkinson's disease
}

\author{
M. J. AMINOFF ${ }^{1}$, M. GROSS, B. LAATZ, S. D. VAKIL ${ }^{2}$, \\ A. PETRIE, AND D. B. CALNE ${ }^{3}$ \\ From the National Hospitals for Nervous Diseases and the Institute of Neurology, \\ and The Hammersmith Hospital and Royal Postgraduate Medical School, London
}

SYNOPSIS The casual arterial blood pressure of 411 patients with Parkinson's disease was compared with that of a representative sample of the general population. The patients were also divided into various sub-groups, and comparisons of blood pressure were made between them. The results provided no support for the widely held belief that blood pressure tends to be low in patients with Parkinson's disease.

The widely held clinical impression that hypertension is rare in patients with Parkinson's disease (Walshe, 1963) has recently been reaffirmed by reports that the blood pressure in patients with Parkinsonism tends to be below or at the lower limit of normal (Yahr, 1970; Barbeau et al., 1971). Moreover, the apparently low blood pressure has been associated with an allegedly reduced incidence of myocardial infarction and cerebrovascular disease in patients with Parkinson's disease (Barbeau et al., 1971). The validity of these conclusions is uncertain, because the data from which they are derived have not been published in detail. This has prompted us to study more fully the arterial blood pressure in an unselected group of patients with Parkinson's disease.

\section{METHODS}

The previously recorded casual blood pressure of 411 patients with Parkinson's disease was compared with the data obtained by Hamilton et al. (1954a) on 2,031 subjects who were considered to be representative of the population at large. This sample of the general population consisted of all outpatients attending the varicose vein, skin, fracture, orthopaedic, and dental clinics at St Mary's Hospital on certain days. The Parkinsonism patients were attending the National

1 Address for correspondence: Dr M. J. Aminoff, Department of Neurology, School of Medicine, University of California, San Francisco, California 94143, U.S.A.

2 Present address: Preston Royal Infirmary, Lancashire.

3 Present address: National Institute of Neurological Diseases and Stroke, Bethesda, Maryland, U.S.A.

Accepted 4 September 1974.)
Hospitals for Nervous Diseases, the Hammersmith Hospital, Royal Free Hospital, or the Preston Royal Infirmary, where blood pressure was measured by a doctor in the outpatient department.

In accordance with the practice of Hamilton et al. (1954a), no account was taken of the presence of coexisting disease, such as chronic nephritis, which might affect arterial pressure, nor of whether the patients were attending the clinic for the first time, and only the first recorded measurement of blood pressure was used. Patients on treatment with levodopa were excluded, since this drug is known to influence the blood pressure.

We had to adopt rigorous criteria for defining idiopathic Parkinsonism for the purpose of this study. Patients with essential tremor, progressive supranuclear palsy, the Shy-Drager syndrome, or atypical movement disorders were excluded, as were patients in whom extrapyramidal signs were present merely as part of a more widespread neurological disturbance. Patients with drug-induced Parkinsonism were also excluded, as were patients in whom a past history of encephalitis or the presence of oculogyric crises or stereotyped tics suggested the possibility of postencephalitic Parkinsonism.

Comparison with the normal population sample was made of the mean observed systolic and diastolic pressure for each five year age group, of each sex. In order to make a more detailed analysis, we also employed the individual age- and sex-adjusted scores for arterial blood pressure, as described by Hamilton et al. (1954b).

The score for an individual is the number of 73 
diastolic pressure differs from the normal predicted from the population average for that age and sex, the score being adjusted to what that deviation would correspond to at the age of 60 years. In other words, it is the numerical value of the extent to which arterial pressure differs from that expected for the normal population at the age of 60 years. This method, which is based on probability theory, is useful in studying blood pressure in selected populations of differing ages and sexes, its advantage being that it enables subjects to be combined to form groups of larger size than would be possible if they were matched for these factors. The scores for each patient were calculated from the tables constructed for this purpose by Hamilton et al. (1954b). The mean scores for the group were compared with those relating only to the 867 subjects drawn from the skin clinic in the original sample of the normal population, rather than to the population sample as a whole, because scores for the former have already been calculated, are readily available, and have been used in subsequent epidemiological studies (Hamilton et al., 1963).

In addition to comparing our collective data with the normal population sample, we compared the arterial blood pressure in various sub-groups of our patients with each other and with the population sample. The patients were divided into three subgroups, depending upon whether tremor, bradykinesia, or rigidity was the most prominent feature of their Parkinsonism, and comparisons were made of their mean systolic and diastolic scores. Comparisons were also made for sub-groups classified by the severity of Parkinsonism, which was assessed by reference to the degree of incapacity. It was graded as mild if there was no incapacity; as moderate if the patient had some incapacity but did not require assistance; and as severe if the patient required assistance.

\section{RESULTS}

ARTERIAL BLOOD PRESSURE IN TREATED AND UNTREATED PATIENTS WITH PARKINSON'S DISEASE There were 325 untreated patients, and 86 on treatment with anticholinergic drugs, in our series. Comparison of the means of the age and sex adjusted scores for systolic and diastolic pressures in these two groups revealed no significant differences $(P>0.05)$. Comparison of the actual measurements showed that there was no significant difference between the groups $(P>$ 0.05 ) in any age group of either sex for systolic and diastolic pressures, except for females aged 55-59 years, when the treated group had slightly
TABLE 1

COMPARISON OF AGE AND SEX ADJUSTED SYSTOLIC SCORES IN VARIOUS GROUP AND SUB-GROUPS OF OUR SUBJECTS*

\begin{tabular}{|c|c|c|c|c|}
\hline Subjects & $\begin{array}{l}\text { Mean } \\
\text { score } \\
(m m)\end{array}$ & Subjects & $\begin{array}{l}\text { Mean } \\
\text { score } \\
(\mathrm{mm})\end{array}$ & $\begin{array}{c}\text { Com- } \\
\text { parison } \\
\text { of } \\
\text { means } \\
t\end{array}$ \\
\hline $\begin{array}{l}\text { Parkinsonism: } \\
\text { Treated cases }\end{array}$ & $-1 \cdot 70$ & $\begin{array}{l}\text { Untreated cases of } \\
\text { Parkinsonism }\end{array}$ & 1.67 & 1.04 \\
\hline All cases & 0.97 & Normal population & -0.05 & 0.62 \\
\hline Cases with: & & Cases with: & & \\
\hline $\begin{array}{l}\text { Tremor } \\
\text { Tremor } \\
\text { Bradykinesia }\end{array}$ & $\begin{array}{r}3.86 \\
3.86 \\
-3.26\end{array}$ & $\begin{array}{l}\text { Bradykinesia } \\
\text { Rigidity } \\
\text { Rigidity }\end{array}$ & $\begin{array}{l}-3 \cdot 26 \\
-1 \cdot 79 \\
-1 \cdot 79\end{array}$ & $\begin{array}{l}2 \cdot 33 \dagger \\
1 \cdot 33 \\
0 \cdot 35\end{array}$ \\
\hline \multicolumn{5}{|l|}{ Cases with: } \\
\hline $\begin{array}{l}\text { Tremor } \\
\text { Rigidity } \\
\text { Bradykinesia }\end{array}$ & $\begin{array}{r}3 \cdot 86 \\
-1 \cdot 79 \\
-3 \cdot 26\end{array}$ & $\begin{array}{l}\text { Normal population } \\
\text { Normal population } \\
\text { Normal population }\end{array}$ & $\begin{array}{l}-0.05 \\
-0.05 \\
-0.05\end{array}$ & $\begin{array}{l}1 \cdot 67 \\
0 \cdot 42 \\
1 \cdot 17\end{array}$ \\
\hline \multicolumn{5}{|l|}{ Cases: } \\
\hline $\begin{array}{l}\text { Mild } \\
\text { Mild } \\
\text { Moderate }\end{array}$ & $\begin{array}{r}0.99 \\
0.99 \\
-046\end{array}$ & $\begin{array}{l}\text { Moderate cases } \\
\text { Normal population } \\
\text { Normal population }\end{array}$ & $\begin{array}{l}-0.46 \\
-0.05 \\
-0.05\end{array}$ & $\begin{array}{l}0.42 \\
0.60 \\
0.12\end{array}$ \\
\hline
\end{tabular}

* The number of subjects was: normal population sample, 867; Parkinsonism patients, 411. The Parkinsonism patients were subdivided into 171 cases with predominant tremor, 115 with predominant $\infty$ bradykinesia, and 48 with predominant rigidity; they were also sub -1 divided into 337 cases with mild, and 70 with moderate disabilit Significant differences are shown as: $\uparrow P<0.05$.

higher pressures than the untreated grou $(\mathrm{P}<0.05)$.

In view of this we have considered it justifiable to combine the data for treated and untreate $\bar{\varphi} \overrightarrow{0}$ cases. We have, therefore, compared data or derived from all the Parkinsonian patients with the data obtained by Hamilton et al. $(1954 a, b)$ for the normal population.

ARTERIAL BLOOD PRESSURE IN PATIENTS WITH PARKINSONISM AND THE NORMAL POPULATION SAMPLE The age and sex adjusted mean scores for these two groups are shown in Tables 1 (systolic scores) and 2 (diastolic scores). There was no significant difference in the mean systolic scores $(P>0.05)$, but the mean diastolic score was higher in the patients with Parkinsonism than in the normal population $(P<0.001)$.

A comparison of the actual blood pressure measurements was also made. The Figure shows separately for each sex the mean systolic and diastolic pressure for each five year age group among the Parkinsonism patients and in the normal population. It can be seen that there were no consistent differences in systolic pressures in the two groups, and this might have been 

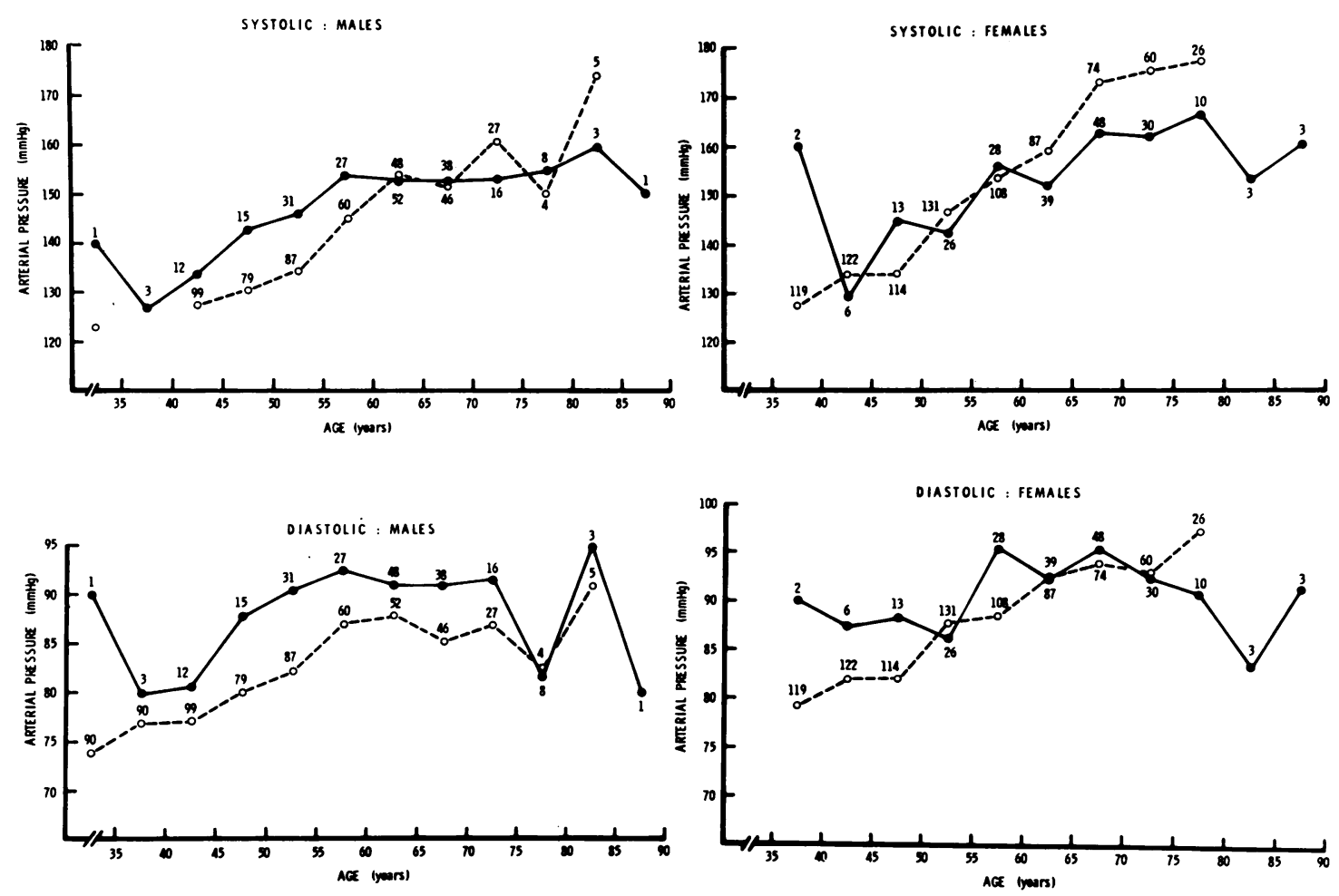

FIGURE The arterial blood pressure in patients with Parkinson's disease, and in the sample of the general population. The mean systolic and diastolic pressure for each five year age group is shown for each sex. The lines join the mean values for the respective age groups, and the number next to each point indicates from how many subjects the means were derived. $-\square=$ patients with Parkinson's disease. $\bigcirc--\bigcirc=$ sample of the general population.

TABLE 2

COMPARISON OF AGE AND SEX ADJUSTED DIASTOLIC SCORES IN VARIOUS GROUPS AND SUB-GROUPS OF OUR SUBJECTS*

\begin{tabular}{|c|c|c|c|c|}
\hline Subjects & $\begin{array}{l}\text { Mean } \\
\text { score } \\
(\mathrm{mm})\end{array}$ & Subjects & $\begin{array}{l}\text { Mean } \\
\text { score } \\
(\mathrm{mm})\end{array}$ & $\begin{array}{c}\text { Com- } \\
\text { parison } \\
\text { of } \\
\text { means } t\end{array}$ \\
\hline $\begin{array}{l}\text { Parkinsonism: } \\
\text { Treated cases }\end{array}$ & $5 \cdot 45$ & $\begin{array}{l}\text { Untreated cases of } \\
\text { Parkinsonism }\end{array}$ & & 0.65 \\
\hline All cases & $4 \cdot 39$ & Normal population & $-0 \cdot 15$ & $4.91 \ddagger$ \\
\hline $\begin{array}{l}\text { Cases with: } \\
\text { Tremor } \\
\text { Tremor } \\
\text { Bradykinesia } \\
\end{array}$ & $\begin{array}{l}5 \cdot 84 \\
5 \cdot 84 \\
2 \cdot 17 \\
\end{array}$ & $\begin{array}{l}\text { Cases with: } \\
\text { Bradykinesia } \\
\text { Rigidity } \\
\text { Rigidity } \\
\end{array}$ & $\begin{array}{l}2 \cdot 17 \\
1.96 \\
1.96 \\
\end{array}$ & $\begin{array}{l}2 \cdot 01^{*} \\
1.43 \\
0.08 \\
\end{array}$ \\
\hline $\begin{array}{l}\text { Cases with: } \\
\text { Tremor } \\
\text { Rigidity } \\
\text { Bradykinesia } \\
\end{array}$ & $\begin{array}{l}5 \cdot 84 \\
1 \cdot 96 \\
2 \cdot 17 \\
\end{array}$ & $\begin{array}{l}\text { Normal population } \\
\text { Normal population } \\
\text { Normal population } \\
\end{array}$ & $\begin{array}{l}-0.15 \\
-0.15 \\
-0.15 \\
\end{array}$ & $\begin{array}{l}4.71 \ddagger \\
0.93 \\
1.58 \\
\end{array}$ \\
\hline $\begin{array}{l}\text { Cases: } \\
\text { Mild } \\
\text { Mild } \\
\text { Moderate }\end{array}$ & $\begin{array}{l}3.75 \\
3.75 \\
5.76\end{array}$ & $\begin{array}{l}\text { Moderate cases } \\
\text { Normal population } \\
\text { Normal population }\end{array}$ & $\begin{array}{r}5.76 \\
-0.15 \\
-0.15\end{array}$ & $\begin{array}{l}0.95 \\
4.08 \ddagger \\
3.05 \dagger\end{array}$ \\
\hline
\end{tabular}

* The number of subjects in each is indicated in Table 1 . Significant differences are shown as: ${ }^{*} P<0.05 ; \dagger 0.001>P<0.01 ; \ddagger P<0.001$. anticipated from the similarity in their age and sex adjusted scores. With regard to diastolic pressures, however, mean values in either sex were in general slightly higher in patients with Parkinsonism than in the normal population.

Statistical analysis of these measurements revealed that among the males the mean systolic and diastolic pressures were higher than those of the normal population in the Parkinsonism patients aged 45-49 years, and 50-54 years $(\mathrm{P}<0.05$ except for diastolic pressure in males aged 50-54 years, when $P<0.01$ ) but there were no other significant differences. Among the females, the only significant difference found in the systolic pressure was in the 70-74 years age group, where values were lower in the Parkinsonism patients than in the normal population $(\mathrm{P}<0.05)$. The diastolic pressures were higher $(\mathrm{P}<0.05)$ in the female patients with Parkinson- 
ism aged 55-59 years than in the corresponding group of the population sample, but there were otherwise no significant differences.

ARTERIAL BLOOD PRESSURE IN VARIOUS SUBGROUPS OF PATIENTS WITH PARKINSONISM In this part of the analysis we have relied solely on the age and sex adjusted scores of systolic and diastolic pressure. This has permitted us to combine data from patients of either sex and different ages, and thus to have sub-groups of moderate size.

Types of Parkinsonism It was possible to subdivide 334 of our patients by the most prominent clinical manifestation of their Parkinsonism. Tremor was the most conspicuous feature in 171 cases, bradykinesia in 115, and rigidity in 48 . The mean systolic and diastolic blood pressure scores for these sub-groups were compared with each other, as shown in Tables 1 and 2. It can be seen that both systolic and diastolic scores were greater in patients with tremor than in those with bradykinesia $(P<0.05)$, but there were no other significant differences. Comparison of the mean scores for each of these sub-groups with the scores for the normal population sample showed no differences $(P>0.05)$, except in the patients with tremor whose mean diastolic score was significantly greater $(\mathrm{P}<0 \cdot 001)$.

Severity of Parkinsonism There were 337 patients with mild, 70 with moderate, and only four with severe Parkinsonism. The number of severely affected patients was small because most patients with this degree of incapacity were receiving L-dopa, and thus were excluded from the series.

There was no difference in the mean systolic and diastolic scores $(P>0.05)$ when the subgroups with mild and moderate Parkinsonism were compared. Comparison of the scores for each of these two sub-groups with those for the normal population sample revealed no difference in their systolic, but a significant increase in their diastolic scores (Tables 1 and 2). The sub-group of severely affected patients was discounted because of the small numbers involved.

\section{DISCUSSION}

Our results show that patients with Parkinson- ism on treatment with conventional anticholiner- $\bar{\phi}$ gic drugs have blood pressures that do not differ significantly from those found in untreated patients. There is little difference in bloodō pressures between patients with mild or moderate ${ }_{\omega}^{\top}$ Parkinsonism and the normal population sample; such difference as does exist consists only of a⿳亠丷厂犬 slight increase in diastolic pressure in the former.? The comparisons lead to similar conclusions $\Rightarrow$ whether they are made by reference to actual $\stackrel{\text { ? }}{\circ}$ measurements or to the age- and sex-adjusted등 scores.

Our data relate to the casual blood pressure, $\frac{\widehat{\Phi}}{\mathrm{Q}}$ and this permits comparison with the large normal population sample of Hamilton et al. ${ }^{\text {s }}$ $(1954 a, b)$. The basal pressure might have been $\vec{P}$ more meaningful in some respects because it is $\vec{\omega}$ obtained under conditions that reduce the influence of environmental and emotional factors, but it is more difficult to determine, has $\stackrel{\bar{\omega}}{\mathrm{\omega}}$ less relevance to the clinical context in which 9 blood pressure is usually measured, and mas itself show some fluctuation (Pickering, 1968). $\frac{\vec{\Phi}}{\mathrm{D}} \mathrm{c}$

The blood pressure in our patients and in the normal population sample was measured at $\vec{a} \vec{c}$ routine hospital visit, but strict comparability between the two groups cannot be assumegl because of differences in the conditions under. which recordings were made. Those of Hamilto et al. (1954a) were made after subjects had been o sitting quietly for five minutes or so, and although this was probably the case in the great majority of our patients, the circumstances were less precisely defined. Such differences in the circum- $\frac{}{\circ}$ stances of measurement were discussed by $\cong$ Hamilton et al. (1954c) who concluded that they might lead to an artificial increase of about $4 \mathrm{mmHg}$ in the mean systolic pressure and of $3.5 \mathrm{~mm}$ in the mean diastolic pressure (when corrected to the age of 60 years). The present findings indicate that in Parkinsonism patients, $\frac{0}{\circ}$ the mean systolic pressure, as predicted to age $60 \underline{3}$ years, is about $1 \mathrm{mmHg}$ higher, and the diastolic about $4 \mathrm{~mm}$ higher than in the normal population sample; if a correction is made for the 의 rather more variable circumstances of measure- $D$ ment, the systolic pressure would then be about $3 \mathrm{mmHg}$ lower, and the diastolic about $1 \mathrm{~mm} \mathrm{~N}$ higher than in the normal population. In either case, therefore, the figures show little difference $N$ from the normal population sample, and thus 
provide no basis for the belief that blood pressure tends to be low in patients with Parkinson's disease.

In view of the present findings, it is important to review earlier reports which suggested that the distribution of blood pressure levels in patients with Parkinson's disease differed from that in the normal population. In some cases (Yahr, 1970; Barbeau et al., 1970, 1971), details were not provided about the circumstances of measurement, and it is not clear whether corrections were made for differences due to age and sex. Aminoff and Wilcox (1971) assessed autonomic function in detail in eight patients with Parkinson's disease who did indeed have a blood pressure lower than that expected for age and sex. However, as these authors indicated, patients were selected for study because they had symptoms suggestive of autonomic dysfunction, and moreover, the degree of incapacity was generally greater in their patients than in those we have now studied. Their conclusions, reaffirmed by Gross et al. (1972), that there may be a supramedullary lesion influencing the regulation of blood pressure in some patients, is not inconsistent, therefore, with the conclusions derived from the present study in a large series of unselected patients without severe incapacity.

Parkinson's disease has a progressive course. Later pathological changes in the thalamus, corpus striatum, hypothalamic nuclei, and brain-stem reticular formation (Foix and Nicolesco, 1925), or increasing inactivity, may lead to a general lowering of blood pressure in more advanced cases than those which we studied, but we can provide no information on this point.

We are grateful to Professor John Marshall for advice; to Dr P. K. Thomas for permission to publish data relating to patients under his care at the Royal Free Hospital; and to the Medical Committee of the National Hospitals for allowing us to publish data from case material at these hospitals. D.B.C. was supported by a grant from the Medical Research Council.

\section{REFERENCES}

Aminoff, M. J., and Wilcox, C. S. (1971). Assessment of autonomic function in patients with a Parkinsonian syndrome. British Medical Journal, 4, 80-84.

Barbeau, A., Gillo-Joffroy, L., and Brossard, Y. (1970). Renin, dopamine and Parkinson's disease. In $L$-Dopa and Parkinsonism, pp. 286-293. Edited by A. Barbeau and F. H. McDowell. Davis: Philadelphia.

Barbeau, A., Mars, H., and Gillo-Joffroy, L. (1971). Adverse clinical side effects of levodopa therapy. In Recent Advances in Parkinson's Disease, pp. 203-237. Edited by F. H. McDowell, and C. H. Markham. Blackwell: Oxford.

Foix, C., and Nicolesco, J. (1925). Anatomie Cérébrale; les Noyaux Gris Centraux et la Région Mésencéphalo-sousoptique. Masson: Paris.

Gross, M., Bannister, R., and Godwin-Austen, R. (1972). Orthostatic hypotension in Parkinson's disease. Lancet, 1 , 174-176.

Hamilton, M., Pickering, G. W., Roberts, J. A. F., and Sowry, G. S. C. (1954a). The aetiology of essential hypertension. 1. The arterial pressure in the general population. Clinical Science, 13, 11-35.

Hamilton, M., Pickering, G. W., Roberts, J. A. F., and Sowry, G. S. C. (1954b). The aetiology of essential hypertension. 2. Scores for arterial blood pressures adjusted for differences in age and sex. Clinical Science, 13, 37-49.

Hamilton, M., Pickering, G. W., Roberts, J. A. F., and Sowry, G. S. C. (1954c). The aetiology of essential hypertension. 4. The role of inheritance. Clinical Science, 13, 273-304.

Hamilton, M., Pickering, G. W., Roberts, J. A. F., and Sowry, G. S. C. (1963). Arterial pressures of relatives of patients with secondary and malignant hypertension. Clinical Science, 24, 91-108.

Pickering, Sir G. (1968). High Blood Pressure, 2nd edn. Churchill: London.

Walshe, Sir F. (1963). Diseases of the Nervous System, 10th edn. Livingstone: Edinburgh.

Yahr, M. D. (1970). General discussion on clinical effects of L-dopa upon blood pressure. In L-dopa and Parkinsonism, pp. 266-268. Edited by A. Barbeau and F. H. McDowell. Davis: Philadelphia. 